\title{
MUDANÇA CULTURAL NO DIREITO: \\ UM EXEMPLO DE PASSO A SER DADO
}

\section{Rodrigo Éder Felício}

Mestrando em Direito pela UNIVEM; especialista em Direito Ambiental e Desenvolvimento

RESUMO: O grande desafio existente hoje está relacionado aos paradigmas utilizados nas mais variadas áreas do conhecimento, sobretudo o direito, com sua cultura que não respeita o indivíduo, a sociedade e suas variadas culturas, limitando seu conhecimento somente a ele próprio. Isto acaba por atrapalhar a própria noção de justiça, uma vez que o conhecimento utilizado desde os tempos de graduação do profissional do direito é de cunho tecnicista, que limita a própria inquietação mental do indivíduo, tornando-o alienado. É este um dos pontos a ser trabalhado e tem como exemplo um grupo pioneiro com uma visão aberta para a complexidade existente da vida cotidiana.

PALAVRAS-CHAVE: Crise paradigmática - observações do cotidiano - ensino jurídico - modelo a ser seguido 


\section{INTRODUÇÃO}

A cada dia que passa, mais uma novidade surpreendente toma conta do mundo. Informação é o que não falta. Basta ligar o televisor e já se sabe o que acontece no Brasil e no mundo.

Estas mesmas informações acabam por modificar até mesmo as próprias culturas dos mais variados povos, uma vez que não estão mais isolados como antigamente, onde a cobertura das informações era limitada.

Esta limitação proporcionava uma certa calma cultural, uma vez que as modificações aconteciam de forma tão lenta e gradual que acabavam por ser imperceptíveis. O mesmo não acontece hoje, pois todos são bombardeados por informações a todo tempo e por todos os lados. Isto influencia em todas as atitudes dos indivíduos, inclusive da sociedade ao qual fazem parte.

Mesmo sendo tão evidente tais movimentos, existem aqueles que o negam, mesmo existindo fatores que demonstrem e comprovem a necessidade de mudanças. Da mesma forma, existem aqueles que conseguem ver essa necessidade de mudança, mas querem algo pronto e acabado para substituir. $\mathrm{E}$ também existem aqueles que querem uma mudança e começam a caminhar passoa-passo, uma vez que sabem que uma guinada drástica contribuiria apenas para a confusão e para uma maior crise paradigmática.

Cabe aqui demonstrar esta crise que atinge as diversas áreas do conhecimento e apresentar um caso de inquietação mental que está trazendo uma esperança para toda esses distúrbios paradigmáticos.

Da mesma forma que a cultura, o direito sofre mudanças ao longo dos tempos e do espaço em que ocupa.

\section{A CRISE NAS DIVERSAS ÁREAS DO CONHECIMENTO E NO DIREITO}

Nas mais diversas áreas de conhecimento, o que mais se questiona é se os atuais paradigmas utilizados na pesquisa estariam apresentando a qualidade necessária para tentar aproximar-se da realidade. E isso não em uma área específica, mas sim nos mais diversos campos do saber desde meados da década de 70 . 
Uma das grandes observações feitas de início era referente à quantidade de pesquisas realizadas, que foram surpreendentemente elevadas e, com isso, surgiu a preocupação para que exista também uma qualidade na produção. É o que afirma Sanches Gamboa ao escrever o artigo "Tendências Epistemológicas: dos tecnicismos e outros 'ismos' aos paradigmas científicos”, que destaca a sua preocupação com a pesquisa e como a mesma está acolhendo os desdobramentos das várias visões de mundo que estariam implícitas na produção da própria pesquisa'.

Em outras palavras, a própria cultura de utilização de apenas uma forma de se observar a realidade está mudando de forma que, além de se ver as questões teóricas e epistemológicas existentes na pesquisa, deve-se observar que existem elementos que irão influenciar no próprio resultado das pesquisas, que seriam todas as influências (concepção de realidade, de mundo e de vida) que o indivíduopesquisador recebeu desde seu nascimento e continua recebendo a cada dia. Estes seriam os pressupostos gnoseológicos (relativo às diversas formas e modos que o indivíduo trata o real, o abstrato e o concreto) e os pressupostos ontológicos (referente às maneiras de se conceber o próprio homem, a sociedade, a educação, a história e a realidade) $)^{2}$.

Com uma visão analógica, pode-se visualizar que o mesmo acontece fora das pesquisas científicas, ou seja, acontece no cotidiano que, por sua vez, estaria relacionado a todas as ciências que têm como objeto, o homem em sociedade, como no caso, o direito ${ }^{3}$.

Todavia, o pensamento dominante no universo jurídico estabelece que o objeto do direito é a norma e não o homem em sociedade. Acontece que este tipo de paradigma não está conseguindo realizar a real justiça, uma vez que ficaria estabelecido que o homem teria de se adaptar às mais diversas regras, pois toda norma seria considerada como legal desde que respeitasse uma norma superior.

Entretanto, nem tudo o que é legal é justo, uma vez que, na maioria das vezes, quando o legislador cria uma norma, ele estaria baseando-se apenas em sua

1 SANTOS FILHO, José Camilo dos; SÁNCHES GAMBOA, Silvio. Pesquisa Educacional: quantidadequalidade. São Paulo: Cortez, 1997, p.60-64.

2 lbid., p. 71.

${ }^{3} \mathrm{O}$ homem em sociedade é considerado neste trabalho como objeto do direito e, em momento algum, irá se discutir se o direito é ou não uma ciência. 
realidade, deixando de lado outras realidades existentes. Ao fazer isso, o legislador estaria contribuindo para a falta de justiça nos mais diversos casos em que a mão positivista de aplicação da norma atuar.

É este paradigma dominante que deve ser rompido e não mais aceito, pois o mesmo não acompanha os movimentos do verdadeiro objeto do direito, deixando, assim, uma grande lacuna entre a justiça positivada e a verdadeira justiça.

Cabe lembrar que tal quebra de paradigmas já está ocorrendo gradativamente, uma vez que o paradigma dominante coloca o direito como a própria fonte de todas as normas. Isto, por sua vez, começa a ser superado por alguns que estariam inconformados com tudo aquilo que está ocorrendo. Tanto é verdade que, para comprenderem como funciona o direito e de como este poderia funcionar, os mais novos (ou atualizados) "cientistas" do direito buscam as razões da norma não mais apenas no próprio ordenamento jurídico, mas sim nas demais ciências, como a sociologia, antropologia, psicologia, filosofia, psiquiatria, enfim, nas mais diversas áreas.

Mesmo sendo observada uma nova tendência paradigmática, profissionais do direito que começaram a romper com os paradigmas newtonianos-cartesianos, mesmo apresentando uma nova forma de pensamento, não conseguirão torná-lo instantâneamente uma realidade, uma vez que já foram contaminados com o pensamento positivado inserido de forma alienante durante seu período de graduação, que nada mais é do que uma incubadora de técnicos em leis. Tal alienação funciona pela repetição insistente de como a teoria é uma coisa linda, e que os manuais, que são seus guias do conhecimento, estabelecem fórmulas prontas e acabadas para os mais diversos casos, onde dificilmente a lei não conseguirá abraçar o caso concreto.

Acontece que os mais diversos casos, mesmo apresentando características comuns, apresentam suas diferenciações, que são frutos das características próprias do indivíduo e que fazem valer-se de acordo com os pressupostos ontológicos e gnoseológicos existentes que irão guiar as diferentes atitudes de diferentes indivíduos a um mesmo caso.

Tais diferenciações dos indivíduos podem ser vistas nas mais variadas realidades, onde, por exemplo, a questão tratada na dissertação de mestrado apresentada na UNESP - Universidade Estadual Paulista é sobre uma realidade de 
favela e um dos assuntos abordados relata sobre uma mulher que morava na favela do Jardim Nacional, em Marília.

Acontece que ele leva uma vida que nós consideraríamos muito desregrada e promíscua. $E$ assim também o consideram os outros moradores da favela que the são vizinhos. Não gostaram das constantes brigas e de coisas que aconteciam em seu barraco. Por isso, aproveitando uma oportunidade em que ela estava ausente, os vizinhos juntaram-se e derrubaram completamente o seu barraco. Ela o reconstruiu bem mais embaixo,no fundo da favela, e continuou sua vida do mesmo jeito que antes. ${ }^{4}$

Isto demonstra que existe uma visão ontológica de toda uma sociedade que não aceita tais atitudes. Acontece que dentro desse pensamento ontológico geral, mesmo ocorrendo uma não aceitação, o máximo que uma pessoa que está inserida nessa sociedade "dominante", que possui mais conhecimento, acaba apenas por excluir as pessoas que não se enquadram naquilo que consideram como o ideal.

Já no caso anteriormente citado, o pensamento ontológico específico não fica apenas na exclusão, mas sim na manifestação física, onde a derrubada do barraco obrigaria a pessoa a fugir dali para não sofrer represálias mais rudes.

Neste caso há uma exteriorização de pensamentos ontológicos específicos de forma física e mais gravosa, onde o então considerado "homem médio", por sua vez, iria concluir que tal atitude (derrubar o barraco) nada mais é do que uma coisa animalesca de tais sujeitos. Acontece que esse homem médio tomou como padrão apenas a sua própria pessoa, ou seja, sua realidade que é composta pelas influências ontológicas e gnoseológicas, deixando de lado o que seria mais interessante no caso concreto, que seria as influências ontológicas e gnoseológicas não desse homem médio, mas sim desses que estão à margem da sociedade em que esse homem médio faz parte.

Desta forma, observa-se uma mesma cultura pode ser interpretada de forma relativamente igual, mas suas atitudes podem ser diferentes; ou pode ser interpretada de forma diferente e suas atitudes relativamente iguais; enfim, irá variar das mais diversas formas, a ponto de surgir diversas possibilidades de interpretação, que ainda sofrerão conforme a história (tempo) e a geografia (espaço).

4 NEVES, Luís Paulo. Signo Dual: leitura semiótica de uma realidade de favela. 1998. $150 \mathrm{f}$. Dissertação (Mestrado)-Curso de Pós-Graduação em Educação, Universidade Estadual Paulista "Júlio de Mesquita Filho", Marília, 1998, p. 74-75. 
Mesmo sabendo que cada indivíduo é diferente e cada situação é única, no universo jurídico isto acaba por ser irrelevante. Com relação à isso, ousa-se aqui dizer que o que falta é um encontro do direito com a cultura existente. Seria um encontro onde o direito deveria apresentar-se de uma forma mais flexível, para que pudesse atender as mais diversas culturas sem prejudicá-las, ou tentando minimizar tais prejuízos.

Isto caberia a todos os profissionais do direito, sobretudo ao juiz, que deveria apresentar uma maior flexibilidade ao caso concreto, estudando-o e tendo em mente que não é mais um caso que se insere nas normas, mas sim de um caso específico que possui uma particularidade própria.

É óbvio que muitos dos positivistas de plantão diriam que isto é utópico, pois segundo o artigo 128 do Código de Processo Civil ${ }^{5}$, o juiz só pode analisar a lide nos limites em que foi proposta, ou seja, a verdade existente é apenas a verdade apresentada nos autos. Acontece que esse mesmo positivista fica preso apenas a uma parte do artigo que, por sua vez, autoriza ao juiz a conhecer tudo aquilo que existe e que pode influenciar nas atitudes do indivíduo que ali está em sua presença.

Todavia isto não é o que acontece, pois o juiz fica preso somente aos autos do processo e o julga, muitas vezes, conforme sua realidade, apesar da alegação da neutralidade do mesmo. Assim, os demais fatores, que são fundamentais por individualizarem o caso, são ignorados em nome de uma provável "acomodação judicial".

A mudança é mais que necessária. É algo essencial para o bom funcionamento da Justiça e da credibilidade das pessoas na máquina do judiciário.

\section{POSSÍVEIS PASSOS A SEREM DADOS NO DIREITO}

Talvez falte um pouco do pensamento dos estóicos no direito, onde se observava a interação de todos os elementos da natureza. Como se fosse uma gigantesca teia de aranha, onde, se um desses fios da teia fossem abalados, poderia comprometer toda a estrutura. O mesmo ocorre no direito, onde as falhas existentes comprometem toda a estrutura da confiabilidade do judiciário.

5 Art. 128. O juiz decidirá a lide nos limites em que foi proposta, sendo-lhe defeso conhecer de questões, não suscitadas, a cujo respeito a lei exige a iniciativa da parte. 
Para reverter tal situação, deve-se observar todos os desdobramentos da realidade existente, como o caso dos ensinamentos ofertados dentro da academia, onde os jovens estudantes de direito, com suas "cartilhas do saber", pregam a "justiça" conforme o que ali está escrito, ou seja, conforme a norma, seguindo passoa-passo a fórmula que a união dos artigos oferece para todos os problemas.

Neste caso, seria necessário desenvolver uma cultura de emancipação dos pensamentos fixos e fictícios de um direito absolutamente puro como alguns querem. Tal pensamento, ousa-se dizer, é algo sem razão. Ora, o direito é como o Brasil, uma vez que ambos são formados pela diversidade, ou seja, o primeiro seria o mesclado de diversas ciências e pensamentos de acordo com o espaço e o tempo existentes; e o segundo é formado pela miscigenação dos mais variados povos e culturas.

Assim, ao se admitir que o direito é fundado e fundamentado nas diversas ciências existentes, o cotidiano passa a ser considerado uma peça importante para o direito. Este cotidiano, por sua vez, seria o ponto em que se cruzam o indivíduo e a sociedade $^{6}$. É esta intersecção que deve ser observada; é esse o momento em que o juiz não pode fechar os olhos; é este o ponto fundamental do próprio direito para o alcance da justiça.

Tais considerações devem ser feitas sempre. Porém, o que acontece na realidade é algo absolutamente contrário, uma vez que os graduandos em direito acabam por terem aulas com professores não preparados para tais funções, uma vez que os mesmos apenas tiveram aulas que levavam ao mero tecnicismo e não a um pensar contínuo. Isto ainda se reflete nas pós-graduações existentes, onde já deveria existir uma inquietação mental e trabalhar com ela, acaba sendo o momento para se excitar e exercitar o raciocínio, começando a deixar de lado o mero conformismo que aceita exacerbadamente a utilização de um tapa-olhos para a realidade e sua complexidade.

É de grande felicidade ressaltar que isso está mudando gradativamente, uma vez que se conta hoje com pessoas que estão dispostas a tentar uma mudança e proporcionar um ensino jurídico de qualidade, onde não se fica limitado aos tecnicismos e ainda, busca-se a inquietação mental dos estudantes de direito.

6 DAHRENDORF, Ralf. Homo Sociologicus: história sobre a história, o significado e a crítica da categoria de papel social. Rio de Janeiro: Tempo Brasileiro, 1969, p. 40. 
Um exemplo disso é a ousadia encontrada no Professor Doutor Celestino Alves da Silva Junior que, por sua vasta experiência em educação e uma inquietação mental surpreendente, criou o Gepedi - Grupo de Estudos e Pesquisas em Pedagogia do Direito, que é o fruto de um trabalho que está se desenvolvendo e que, por sua vez, estará sendo implantado no programa de mestrado da Fundação Eurípedes de Marília - Univem.

Tal ousadia em criar uma nova disciplina está na não conformidade com os paradigmas atuais existentes, que acabam por não conseguir abranger as diversidades existentes e, ainda, por abolir o pensamento dos futuros profissionais do direito, uma vez que estes sofrem um processo de alienação que cria apenas tecnólogos de leis. Em outras palavras, o que o pioneiro professor Celestino visa é sanar a problemática do educador do direito, que encontra-se limitado ao tecnicismo jurídico.

É óbvio que falta muito ainda o que fazer para que ocorra realmente uma mudança, pois é necessário que as dependências existentes sejam supridas. Uma dessas dependências, como no caso anteriormente citado, já começa a caminhar para sua emancipação, mas existem muitas outras que deveriam ser analisadas.

A criatividade seria uma peça fundamental para isso. Mas para se ter tal criatividade, necessário se faz despertar isso dentro de cada um. É isso que o Gepedi propõe e é isso que muitos pensadores acabam buscando quando buscam uma independência de pensamentos.

É essa independência de pensamentos que se almeja tanto nos dias atuais. É a não aceitação de idéias que não fazem parte da realidade cotidiana. É a busca por uma razão própria.

É claro que não se pode pôr em dúvida que os pensamentos anteriores devem ter sua relevância, como no caso do direito, os pensamentos de Kelsen. Não se pode negá-los, uma vez que os mesmos faziam parte de sua realidade (espaço e tempo) e, ainda, tinha suas ressalvas pois buscava uma pureza no direito para deixá-lo como uma ciência.

Todavia, o que se observa, é que os juristas acabam por querer usar tudo aquilo que Kelsen dizia ser a realidade própria e imutável do direito. Dizer que ele errou seria uma aberração intelectual, pois era sua verdade e toda verdade bem fundamentada é válida. 
Mas o que deve ser relembrado é que somente com novos pensamentos sobre os já estabelecidos é que se pode ocorrer uma evolução. Ficar preso ao passado apenas contribuirá para uma estagnação e, no caso do direito, ficaria absolutamente ultrapassado.

Assim, "a máxima fidelidade a um mestre é abandoná-lo. É jamais deixar que seu pensamento vire fórmula vazia. Não deixar que a originalidade de sua intuição morra na esterilidade de um conceito. Fazer o que um mestre fez não é fazer o que fez, mas o que faria se estivesse em nosso lugar”" Em outras palavras, não se pode criar um conformismo com aquilo que já não atende as atuais necessidades.

Por mais absurdo que seja, isso é algo da cultura dominante, onde parece que envelhecer é caminhar para o futuro. Muito pelo contrário, pois quanto mais se atualiza, mais dentro do presente se está inserido e mais próximo do futuro se chega. Nessas condições, ficar repetindo infindavelmente as mesmas repostas que um dia já foram algo novo, criador, pode muitas vezes não condizer com a atual realidade, tornando-se esta prática algo absolutamente perigoso.

Essa cultura de conformismo, principalmente dentro do direito acaba por deixar as necessidades humanas e o compromisso da transformação social em segundo plano, uma vez que os mesmos não aparecem na seleção dos conteúdos, nem na metodologia utilizada e, sobretudo, na sistemática de avaliação ${ }^{8}$.

Para tanto, deve-se ter em mente que o conhecimento é uma porta que não pode fechar. Deve estar aberta para que as idéias possam caminhar livremente e apresentar alternativas e respostas aos mais diversos questionamentos.

\section{CONSIDERAÇÕES FINAIS}

Observa-se que nas mais diversas áreas do conhecimento, para se realizar uma pesquisa, o pesquisador nunca começa de um ponto zero, pois sempre haverá os pressupostos gnoseológicos e ontológicos e que, por sua vez, irão até mesmo interferir no próprio resultado da pesquisa.

7 GOMES, Roberto. Crítica da Razão Tupiniquim. 10a․ ed. São Paulo: FTD, 1990 (Prazer em Conhecer), p. 107.

${ }^{8}$ D’ANTOLA, Arlette (Org.). A Prática Docente na Universidade. São Paulo: EPU, 1992, p. 16. 
Isto se reflete no direito em diversos pontos, como no caso da criação das normas, que podem vir atender apenas uma parte da realidade e não o seu todo, atrapalhando atingir a real justiça. Reflete-se também na própria aplicação da lei ao caso concreto, onde, em muitas vezes, acabam por considerar o magistrado como se estivesse no Olimpo das normas, onde a interpretação dada por ele é a única correta, mesmo sem essa condizer totalmente com a realidade ignorada dos autos.

São esses e outros pontos que devem ser revistos e trabalhados de forma a tentar minimizar os estragos causados ao homem e à sociedade pelo despreparo de muitos profissionais do direito que não conseguem ver as mudanças sociais que estão cada dia mais evidentes e, por isso, exigem cada vez mais uma compreensão de todas as verdades articuladas existentes que compõe toda a complexidade do cotidiano.

É por isso que pequenos passos podem se tornar uma gigantesca empreitada, como a que está sendo realizada pelo Profo. Dr. Celestino com o Gepedi.

\section{REFERÊNCIAS BIBLIOGRÁFICAS}

ASSIS, Olney Queiroz. O Estoicismo e o Direito: justiça, liberdade e poder. São Paulo: Lúmen, 2002.

COTRIM, Gilberto. Fundamentos da Filosofia: história e grandes temas. 15ª. ed. ref. e ampl. São Paulo: Saraiva, 2000.

D’ANTOLA, Arlette (Org.). A Prática Docente na Universidade. São Paulo: EPU, 1992.

DAHRENDORF, Ralf. Homo Sociologicus: história sobre a história, o significado e a crítica da categoria de papel social. Rio de Janeiro: Tempo Brasileiro, 1969.

FAGÚNDEZ, Paulo Roney Ávila. O Direito e a Hipercomplexidade. SãoPaulo: LTr, 2003.

GOMES, Roberto. Crítica da Razão Tupiniquim. 10å ed. São Paulo: FTD, 1990 (Prazer em Conhecer).

HERKENHOFF, João Baptista. Direito e Utopia. 5a.. ed. Porto Alegre: Livraria do Advogado, 2004.

NEVES, Luís Paulo. Signo Dual: leitura semiótica de uma realidade de favela. 1998. $150 \mathrm{f}$. Dissertação (Mestrado)-Curso de Pós-Graduação em Educação, Universidade Estadual Paulista "Júlio de Mesquita Filho", Marília, 1998.

PEREIRA, Aloysio Ferraz. Estado e Direito na Perspectiva da Libertação: uma crítica segundo Martin Heidegger. São Paulo: RT, 1980. 
SANTOS FILHO, José Camilo dos; SÁNCHES GAMBOA, Silvio. Pesquisa Educacional: quantidadequalidade. São Paulo: Cortez, 1997.

WARAT, Luis Aberto. Os Quadrinhos Puros do Direito. Argentina: Angra Impressiones, [19--?]. 